\title{
Proceeding
}

Supplementary Issue: Summer Conferences of Sports Science. First International Conference in Iraq on Sport for Peace, 4 April 2019. Baghdad Science Institute, Baghdad, Iraq.

\section{Does the e-marketing determine the sustainable performance of firm's Sportswear industry in Thailand}

\author{
SUDAWAN SOMJAII ${ }^{1}$, SUMALEE SRISUPONVANIT ${ }^{1}$, KITTISAK JERMSITTIPARSERT ${ }^{2,3}$ \\ ${ }^{1}$ Graduate School, Suan Sunandha Rajabhat University, Bangkok, Thailand \\ 2Department for Management of Science and Technology Development, Ton Duc Thang University, Ho Chi \\ Minh City, Vietnam \\ ${ }^{3}$ Faculty of Social Sciences and Humanities, Ton Duc Thang University, Ho Chi Minh City, Vietnam
}

\begin{abstract}
The main objective of the study is to explore the e-marketing as a determinant of the sustainable performance of firm's Sportswear industry in Thailand. The present study is unique because of its focus on the e marketing in general and its impact on the sustainable organizational performance. Empirical evidence has been provided by this study for the hypothesized theoretical associations in accordance with the research framework. The study has surveyed the sportswear manufacturing firms. The final sample is 238 and response rate is 43 percent. The SEMPLS is used to analyse the data. The findings of the study have provided support to the hypothesized results. Several important implications can be made by this research. The research has identified several relations with regard to the literature on sustainability. The study has tested the direct and indirect relations among the variables, which were identified by the literature. The understanding of managers for achieving sustainable business performance through use of e marketing practices can be enhanced by the suggested model. Moreover, the e marketing process improves when it involves the technological aspects. From practical aspects, the study motivates the shareholders, top management, government, marketing department, policy makers, and practitioners to improve the sustainability of business. Keywords: E-marketing; Sportswear industry; Sustainability; Thailand.
\end{abstract}

Cite this article as:

Somjai, S., Srisuponvanit, S., \& Jermsittiparsert, K. (2019). Does the e-marketing determine the sustainable performance of firm's Sportswear industry in Thailand. Journal of Human Sport and Exercise, 14(5proc), S2304S2317. doi:https://doi.org/10.14198/jhse.2019.14.Proc5.46

Corresponding author. Department for Management of Science and Technology Development, Ton Duc Thang University, Ho Chi Minh City, Vietnam.

E-mail: kittisak.jermsittiparsert@tdtu.edu.vn

Supplementary Issue: Summer Conferences of Sports Science. First International Conference in Iraq on Sport for Peace, 4 April 2019. Baghdad Science Institute, Baghdad, Iraq.

JOURNAL OF HUMAN SPORT \& EXERCISE ISSN 1988-5202

(C) Faculty of Education. University of Alicante

doi:10.14198/jhse.2019.14.Proc5.46 


\section{INTRODUCTION}

When a firm gives value to its stakeholders complying with the environmental standards, it becomes able to make its performance sustainable (Baumgartner \& Rauter, 2017). For making the business processes efficient, there is need for considering sustainability. It is crucial to develop a corporate culture, which is constructive and developing, to achieve transition towards sustainability (Kamali \& Hewage, 2017). The performance of an organization is made better and the current assets can be used optimally through developing a healthy culture for improvement business performance (Jermsittiparsert \& Srihirun, 2019). The performance of the organization is improved in terms of environment, economic and social development (Śmigielska, 2018; Jermsittiparsert, Sutduean, \& Sutduean, 2019).

The top management, customer, society, employees, and stakeholders become satisfied with the improvement in terms of society, environment, and economy. Global businesses are experiencing issue in adopting development practices, which are sustainable. Three crucial pillars form the sustainability concept that includes society, environment, and economy. These are referred as triple bottom line as well. Several research fields including engineering, environmental and social sciences have recognized the concept of sustainability (Najam, Awan, \& Abbas, 2018; Yigitcanlar \& Teriman, 2015). From every aspect such as the way in which companies respond to the needs of customers in society through sustainable practices is considered by the triple bottom line in the textile sector. Moreover, the way in which societal forces are linked with the sustainable performance is also the focus of triple bottom line along with economic performance. The sports sector is making great contributions to GDP through job creation. The previous research studies reveal that the more than 15 million jobs are created by the Thailand's sports sector, which contribute about $9.5 \%$ of total GDP of the economy (Ataullah et al, 2014). The figure 1 highlight that in 2018 the sportswear sale has grown in Thailand.

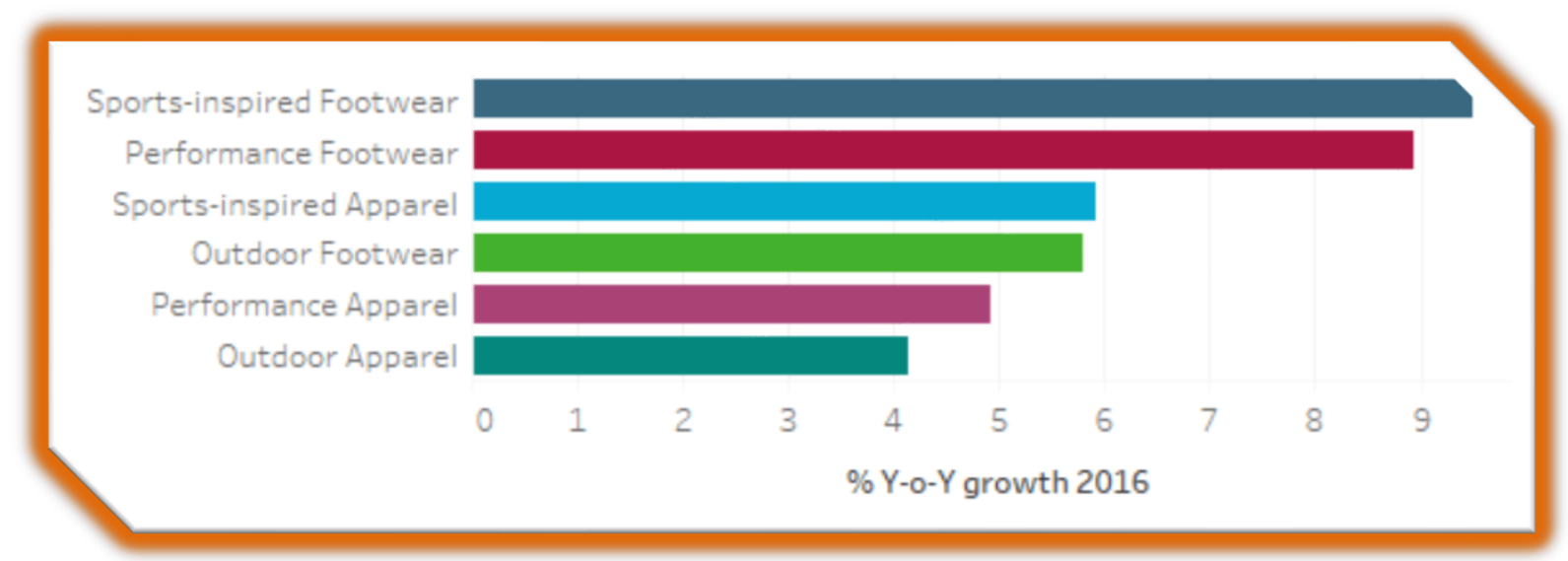

Figure 1. Sportswear growth in 2016.

From the environmental aspect, firms in textile sector have ISO 14001 certification while some firms are still approaching the environmental standards. It is important to know the way in which government, e-marketing, trading partners, top management and competitors are supporting the firms in the achievement of high and sustainable performance of the business in line with the tipple bottom line. This question has remained unanswered by the previous studies. In this research, the indirect and direct influence to analyse the importance of issue of sustainability with regard to the sports sector of Thailand. Diverse issues are being 
experienced by every country particularly the manufacturing sector. This sector is mainly responsible for the issues of triple bottom line. One of the biggest concerns in businesses has become sustainability because of greater emissions of CO2 and generation of waste (Wong \& Zhou, 2015). With the passage of time, the employment in manufacturing sector is becoming worse. Several companies have closed leaving a number of people unemployment. In Thailand, the aspects of triple bottom have been by the competitors. A crucial role has been played by the top management and CPs of the competitors in region in uplifting of their sector. Stagnation has been experienced by Thailand in the sports sector but the countries including India, China, and Bangladesh have sustained their ranking (World Trade Organization). New electronic channels have been developed by rapidly developed information technology. It is important to provide online services of the customers for their satisfaction (Hyung \& Dedahanov, 2014; Sheikh, Shahzad, \& Ishaq, 2017). The changing aspects of revolutionized media have created several issues. The previous researchers have emphasized on the implementation of e-marketing tools by SMEs to achieve sustainability (Georgios \& Theoharis, 2017; Pinho, 2015). Business in the emerging regions is not much focused by the researchers, which results in research gap. Countries such as Thailand have limited innovation and use of e marketing (lqbal, Mahmood, \& Akhtar, 2017; Sadeghi, Sobhani, \& Ghatari, 2017; Vafaei, Azmoon \& Fekete-Farkas, 2019).Similarly, the countries including India, China, and Bangladesh have become competitors of Thailand and consumers have shifted to them over the previous some years (Kowo, Adenuga and Sabitu, 2019; Wagdi and Hasaneen, 2019). The foreign buyers are continuously trailed by the manufacturing sector because of poor policies of government, low competitiveness, lack of support from top management (TMNS), TOP (lack of technological opportunism), and poor CPs relations along with lack of e-marketing. All these factors have resulted in low sustainable performance (Sheikh, Shahzad, \& Ishaq, 2017). The export of garments results in $\$ 21$ billion revenue in 2013 for Bangladesh. However, Thailand earned revenue of $\$ 2.6$ billion. This revenue constitutes almost 90 percent of the total foreign exchange revenue of China. Irrespective of the substantially organized sports sector of Thailand, and China are leading the industry because of latest technological revolutions including adoption of e-commerce. The top management should work on implementing e-marketing technology to advance the sector and improve the sustainable business performance (Sheikh, Shahzad, \& Ishak, 2016; Sheikh, Shahzad, \& ku Ishak, 2017). It has been verified by (Snyder \& Hilal ,2015) that a shift has been observed over the past five years in digital business-to-business marketing. However, currently, the digital marketing should be implemented by every business to sustain in the environment. The buyer's interest can be captured by adoption of e-marketing tools. For improved performance, advancement of technology and its implementation by the firms has become a main obstacle in the current business world. It has been corroborated by some research studies that there is a gap between the firms and customers in terms of communication. The adoption of e-business has been restricted by several factors including unfavourable trends in the market and global competition. In China, there has been almost 20 percent rise in the e-commerce trade. Alternatively, the benefits linked with the use of e marketing have not been considered in Thailand (Sheikh et al., 2016; Sheikh, Shahzad, \& ku Ishak, 2017). The present study is unique because of its focus on the e marketing in general and its impact on the sustainable organizational performance. Empirical evidence has been provided by this study for the hypothesized theoretical associations in accordance with the research framework. The role of USEM as a mediator has been highlighted by this study along with the role of CP and CPs as moderators between UCM and TCM. Alternatively, the study explores the role of GS and TOP as moderation between the association of SFP and USEM. The research implications are related to defining the use of RBV and DOI along with improving the ability of the organizations to adopt technology for attaining sustainable business performance. In this regard, the studies in future can work with the focus on effect of USEM and TMNS on the sustainable performance. Moreover, the model can be extended by future studies through use of environmental, organizational, and technological factors. Further, future studies can incorporate the role of e-business, innovation, and e-commerce as mediating variable using the DOI and RBV theories. The research has been presented in the form of different sections. The 
section 2 involves the development of hypothesis and conceptual framework. In Section 3, the methodology has been focused to achieve the desired results of the study. In Section 4, the collected data has been analysed. In section 5, the results have been interpreted and discussed. The practical and theoretical implications of the study along with its limitations have been presented in this research.

\section{CONCEPTUAL FRAMEWORK}

Several theories have focus on the use of technology and improved performance (Haseeb et al, 2019; Sutduean et al, 2019). Some of these theories include theory is technology acceptance model, unified acceptance theory and use of technology, and theory of planned behaviour (Fitzgerald \& Stol, 2017; Lowry \& Wilson, 2016). A limited number of studies have analysed the influence of such theories on the firm level. This research RBV has been used to address SFP (sustainable firm performance). In 1991, Berney recommended that innovation could be used to achieve and sustain competitive edge. Firms can improve their performance through innovation or creation of resources, which are rare, non-substitutable, valuable, and inimitable. This is in line with the diffusion of innovation theory, which is also regarded as DOI theory. Contributions have been made in this study by relating with RBV theory to improve the research scope in the countries like Thailand. In Thailand, the use of technology is still in the emerging state and organizations demand the empirical contributions to the sustainable performance of business. This study has made explicit contributions by defining the antecedents of sustainable performance of business that is TMNS and e marketing. An intervening construct has been used by the role of e marketing between the relation of SFP and TMNS. This relation has been determined by incorporating different unique variables including $C P$ (competitive pressure), CPs, TOP, and GS (government support). These variables were based on RBV and $\mathrm{DOI}$ that define the way in which technological diffusion can improve the performance of firm. The previous research studies have not incorporated these variables and theories. Therefore, the theoretical relation among the variables has not been explained by any studies in the aspect of mediated-moderation and moderated-mediation analysis through use of Smart PLS SEM method. The existing knowledge has been extended by the current study by incorporating innovation as a mediator in accordance with RBV theory. SFP has been analysed by RBV and technology theory (Spreer \& Rauschnabel, 2016). The sustainable performance of businesses in Thailand can be enhanced as per the results of this study. A significant role has been played by the top management in implementing latest technology in the firms (Damanpour, Sanchez, \& Chiu, 2018). Several factors constitute sustainable performance of a business that is related to the internal and external environment. The core competency of the firm can be maintained by some factors. The focus of the firms has increased in making better decisions due to the fact that improvement in technology reduces the life cycle of product. In this way, there is need for the firm to become competitive in analysing the trends in market. It has been realized by firms over some recent years that the use of digital marketing can enable better decision making for improved sustainable performance. According to $\mathrm{DOI}$, a leading role has been played by the top management in adopting new technology. It has been highlighted by several studies that there is need for TMNS, which will offer idealistic leadership to express the requirement of innovation including e marketing (Pappu \& Quester, 2016). Moreover, it has been explained by (Hawary \& AIDafiri ,2017) that commitment of top management enable the firm to adopt the latest technology such as e marketing for eliminating the gap in communication among the customers and improve sustainable performance of business. The top management in the sports sector of Thailand recruits' processionals to deal with the information system. However, the top management feels reluctant to adopt latest technology because of lack of knowledge. For this reason, the sports sector of Thailand is far behind in the global competition and cannot address the issues of sustainability such as environment, social integration, and economic contribution. Therefore, there is need to deal with issues of adopting e marketing to enhance the sustainable business performance. For increase in market share, revenue, growth, cost efficiency and new 
product development, TMNS has a significant role in technological adoption. This can help in customer retention for long term (Tiago \& Veríssimo, 2014). The above discussion leads to the formulation of the following research hypothesis:

H1: Top management support has a significant impact on the use of e-marketing of sportswear in Thailand.

H2: Top management support has a significant impact on the use of sustainable performance of sportswear in Thailand.

A crucial role is played by the use of ICT related to the marketing activities in enable the global operations of firm. It has also become a source of competitive advantage for the firms in comparison to others who are not much specialized in the adoption of ICT. Moreover, the marketing department becomes able to communicate with the customers by reduction in the communication cost (tangible and intangible). It has become difficult to acquire greater profit margins in the economies based on knowledge. This is because of intense competition and number of products offered. Moreover, there has been reduction in the product cycle time and decision-making. There is need for rapid alignment of the business with latest marketing techniques and effective decision-making. The previous research studies have shown mixed results for the influence of $e$ marketing on sustainable firm performance. The positive impact has been supported by some researchers (Bi, Davison, \& Smyrnios, 2017). Some studies have evidenced that the use of e marketing results in improved competitive position and financial gain for the firms. However, the benefits of e marketing vary with the size, region, and sectors. In the same perspective, the use of e marketing results in comprehended benefits (Bi, Davison, \& Smyrnios, 2017). Irrespective of the claims, there is need for understanding the USEM in the businesses, which can contribute in better and sustainable performance of business. Limited studies have analysed the association between the two unobserved constructs. The previous research studies have incorporated the adoption of e commerce an innovation as mediators to analyse the performance of businesses. The previous research studies have neglected the SFP to be mediated by $e$ marketing. The focus of traditional scholars have been on the western organizations and it is crucial for the Thailand firms to incorporate e marketing practices to achieve sustainable performance in the sports sector (Sadeh \& Kacker, 2018). It was recommended by (Iddris \& Ibrahim ,2015) that it is important to develop a relation between sustainable performance of business and e marketing. This research has analysed the influence of e marketing adoption on sustainable business performance in the Sports sector of Thailand. Considering the above discussion, the following research hypothesis has been formulated:

H3: The use of e-marketing has a significant impact on the use of sustainable performance of sportswear in Thailand.

In order to motivate a firm for investment, $\mathrm{CP}$ is considered as a vital external variable. Most of the companies are adopting latest technology to increase their market share in the local and global markets. Many research studies have signified that the top management is motivated by CP to determine the strengths and weaknesses of competitors to make its resources unique (inimitable, rare, non-substitutable, and valuable. The focus of previous researches has been on the competitive strategy and competitive advantage to improve the performance of business. It has been revealed by these studies that their scope cannot be generalized. Moreover, the moderating influence of $\mathrm{CP}$ has been analysed empirically by this research, which is a key contribution to the current theories and literature. For growth of business, CP is a crucial element and it enables the firm to become sustainable towards economic and social contribution. The firms are motivated to become environmentally sustainable. CP influences the technological adoption, decision of top management to achieve ethical profits in business and sustainable performance. It was indicated by (Abu Bakar \& Ahmed ,2015) that there are various factors, which enable the adoption of technology in business. One of the main reasons is CP that reflects that the major goal of the firms is to achieve competitive advantage, efficiency, and effectiveness. It was indicated by a study that the focus of client server technology 
is on competitors, efficiency, and operations for conducting a specific task. These variables have been considered as indicators driven by the business and technical. The following hypothesis has been formulated based on the above discussion.

H4: The competitive pressure moderates the relationship between use of e-marketing and sustainable performance of sportswear in Thailand.

The role of GS as moderator between the relation of SFP and USEM is considered as a crucial element for the adoption of latest technology. The firm is pushed by the government to adopt B2B electronic marketplace for carrying out the marketing tasks. The firms have been motivated by the government in the Asian region to adopt B2B e business. This is regarded a crucial factor in the business environment. The willingness of a country towards the growth of business is dependent on the use of electronic media. This is based on the support of government such as grants of government, promotional activities, and regulatory values. These initiatives enable the digital trading environment. The support of government is required for making the effective use of innovative technology. Moreover, for avoiding the ineffective information between the buyers and suppliers, the cybercrime security is used. The current research involves an empirical investigation to examine the encouragement of government for use of e marketing to achieve sustainable performance of business. The focus of the companies should be on combining the sustainability, marketing, and technology for improved performance to comply with the issues of triple bottom line. The social attributes cannot be achieved by the company without processing of technology in terms of extranet and intranet for the benefit of the organization. In China, e-commerce is used for improving the financial gains of the firms. The business is provided with a consistent environment by the government for doing e-business to get improved performance. E-commerce is being encouraged by several countries such as Australia, USA, Singapore, Canada, and other members of EU through some changes in the legal policies (Jameel \& Ahmad, 2018). There is need for more support in literature regarding the sports sector and the policies for enhancing the use of e-business. Moreover, GS has been used by a number of studies as an explanatory factor with reference to the SMEs in the western countries (Rahayu \& Day, 2015). Some studies have used GS with reference to the emerging economies such as Thailand, India, Saudi Arabia, Taiwan, etc. (Ueasangkomsate, 2015). However, GS has not been used as a moderator by any research between the relation of sustainable performance and USEM. Irrespective of this, the researchers have overlooked the influence of e marketing. In order to define the significance of GS towards the use of e marketing and sustainable performance, empirical investigation is required. The above discussion results in the formulation of following research hypothesis:

H5: The government support moderates the relationship between use of e-marketing and sustainable performance of sportswear in Thailand.

\section{MEASUREMENTS AND METHODOLOGY}

This research study has adopted the measures and constructs from the previous studies after the reliability test, which consisted for questionnaire. In the pilot study, 35 filled questionnaires were examined, and these were omitted from the research analysis. Moreover, the questionnaire survey was carried out between two divisions. A 7-point Likert scale item was used in the first division and demographic information was involved in the second division. The 7-point Likert scale was used in this research to provide more options to the respondents. It can provide a clear understanding to the researcher about the respondents' attitude and behaviour. 4-itme scale has been used for measuring TMNS, which has been adopted by (Alsaad et al, 2017). For measuring the CPs pressure, a 2 -item scale has been used given by 2 -item. A 6 -item scale has been used to measure CP, which was proposed by (Cameron \& Green ,2015). An 8-item scale was adopted for measuring TOP developed by (Pappu \& Quester ,2016). A 4-item scale has been used for determining 
the support of government proposed. Moreover, USEM was measured using 8-item scale proposed by (Pappu \& Quester ,2016). Further, a 7-item scale was used to define the economic, social, and environmental factors of sustainable firm performance proposed.

\section{DATA ANALYSIS}

This research study involved the use of SEM-PLS 3.0 for the evaluation of outer and inner model (measurement and structural). The direct, moderating as well as mediator effects were analysed through SEM-PLS method. The two important aspects in the PLS-SEM approach include the determination of reliability and validity of the outer model (Davcik \& Sharma, 2016; J. F. Hair et al, 2016). The measurement model is shown in the figure 1 below.

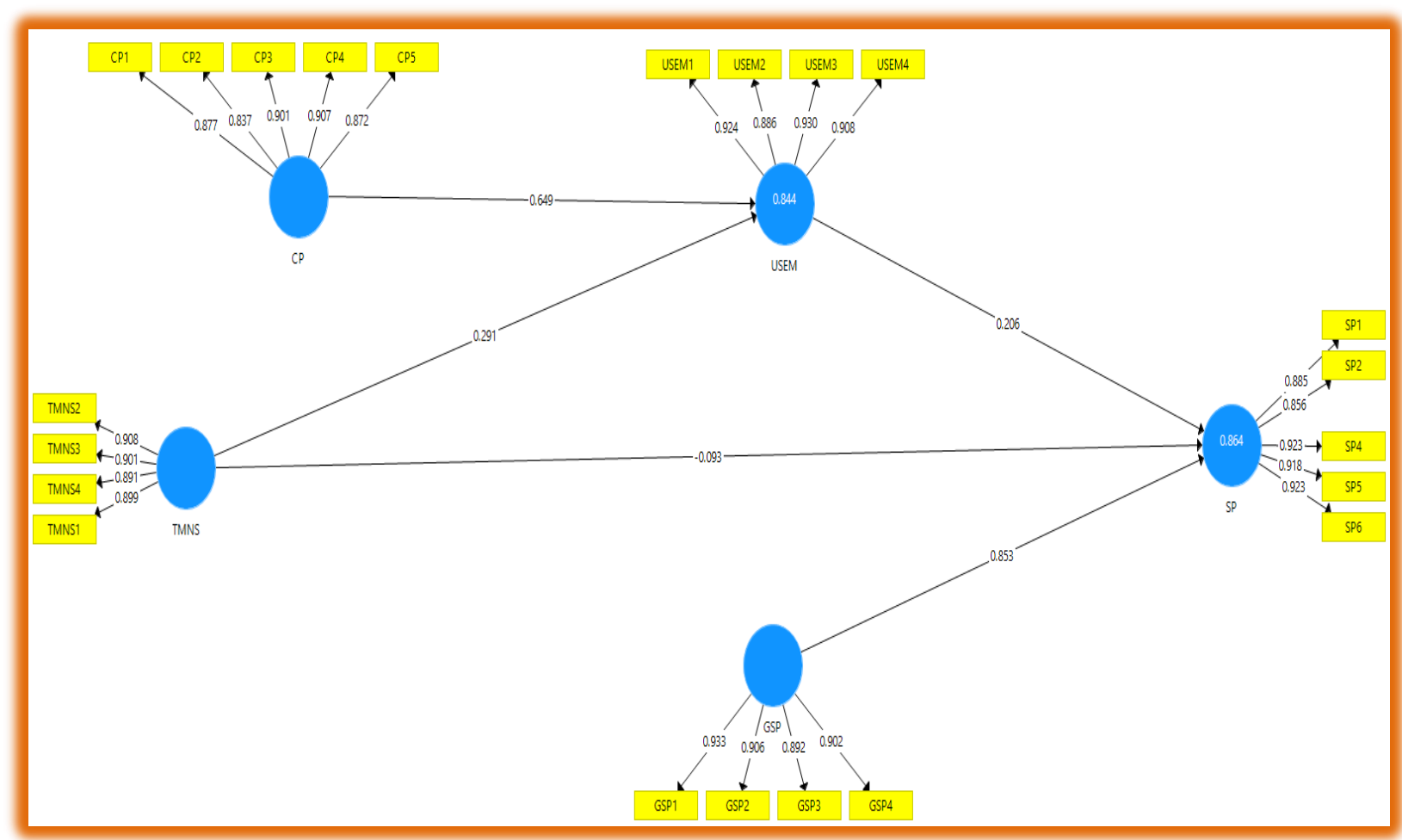

Figure 2. Measurement model.

Table 1. Outer loadings.

\begin{tabular}{|l|l|l|l|l|l|}
\hline & CP & GSP & SP & TMNS & USEM \\
\hline CP1 & 0.877 & & & & \\
\hline CP2 & 0.837 & & & & \\
\hline CP3 & 0.901 & & & & \\
\hline CP4 & 0.907 & & & & \\
\hline CP5 & 0.872 & & & & \\
\hline GSP1 & & 0.933 & & & \\
\hline GSP2 & & 0.906 & & & \\
\hline GSP3 & & 0.892 & & & \\
\hline GSP4 & & 0.902 & & & \\
\hline
\end{tabular}




\begin{tabular}{|l|l|l|l|l|l|}
\hline SP1 & & & 0.885 & & \\
\hline SP2 & & & 0.856 & & \\
\hline SP4 & & & 0.923 & & \\
\hline SP5 & & & 0.918 & & \\
\hline SP6 & & & 0.923 & & \\
\hline TMNS2 & & & & 0.908 & \\
\hline TMNS3 & & & & 0.901 & \\
\hline TMNS4 & & & & 0.891 & \\
\hline USEM1 & & & & & 0.924 \\
\hline USEM2 & & & & & 0.886 \\
\hline USEM3 & & & & & 0.930 \\
\hline USEM4 & & & & & 0.908 \\
\hline TMNS1 & & & & 0.899 & \\
\hline
\end{tabular}

The reliability and validity of the model determines the nature of relation among the variables. The individual item reliability can be used to determine the sufficiency of the outer model. It involves testing the indicator reliability and internal consistency reliability through composite reliability. Further, AVE is used to determine the convergent validity. The criterion of Fornel-Larcker is used to assess the discriminant validity and the outer loadings of the indicator (Henseler et al, 2015). The result of the AVE should be equal or greater to 0.50 for sufficient convergent validity. The AVE values have been used to determine AVE. the AVE value for all the constructs has been shown in Table 2 and it reflects that all the values are greater than the standard value (Hair et al, 2017). The values of AVE for all the constructs range between $0.52-0.83$. Therefore, it can be said that the model has sufficient convergent validity. The external consistency of the model was determined through discriminant validity, which has been shown in Table 3. Table 2 also defines the comparison between the unobserved constructs.

Table 2. Reliability.

\begin{tabular}{|l|l|l|l|l|}
\hline & Cronbach's Alpha & rho_A & CR & (AVE) \\
\hline CP & 0.926 & 0.927 & 0.944 & 0.773 \\
\hline GSP & 0.929 & 0.930 & 0.950 & 0.825 \\
\hline SP & 0.942 & 0.943 & 0.956 & 0.812 \\
\hline TMNS & 0.922 & 0.922 & 0.945 & 0.810 \\
\hline USEM & 0.933 & 0.935 & 0.952 & 0.832 \\
\hline
\end{tabular}

Table 3. Discriminant Validity.

\begin{tabular}{|l|l|l|l|l|l|}
\hline & CP & GSP & SP & TMNS & USEM \\
\hline CP & 0.879 & & & & \\
\hline GSP & 0.790 & 0.908 & & & \\
\hline SP & 0.734 & 0.822 & 0.901 & & \\
\hline TMNS & 0.795 & 0.773 & 0.761 & 0.900 & \\
\hline USEM & 0.710 & 0.740 & 0.771 & 0.872 & 0.902 \\
\hline
\end{tabular}

In order to get the answers of research questions, the effects of multiple relations have been identified through PLS-SEM method. The relationship testing includes indirect, direct, moderating, and mediating effects. For mediating relations, the technique of bootstrapping has been used. To assess the moderating relations, the approach of product indicator has been used. This has been represented in the Figures 3. Smar PLS 3.2.7 
has been used to assess the structural model and regression. The dependent of the variables is estimated in the structural model. The direct relations are analysed in PLS through path coefficients and t-values. It was signified by (Henseler et al, 2015) that the path coefficient and standardized beta are same in regression analysis. The significance of the association has been identified through use of t-values. The t-value should be higher than the 1.64 value for significant relation to draw result about the hypothesized relations (Hair et al, 2014). 5000 iterations and 293 responses were done to estimate the t-values, coefficients, and beta values (Hair et al., 2014). Three hypotheses are included in this research consisting of direct association among the variables. The direct and moderating influence of every variable has been validated in Figure 3 .

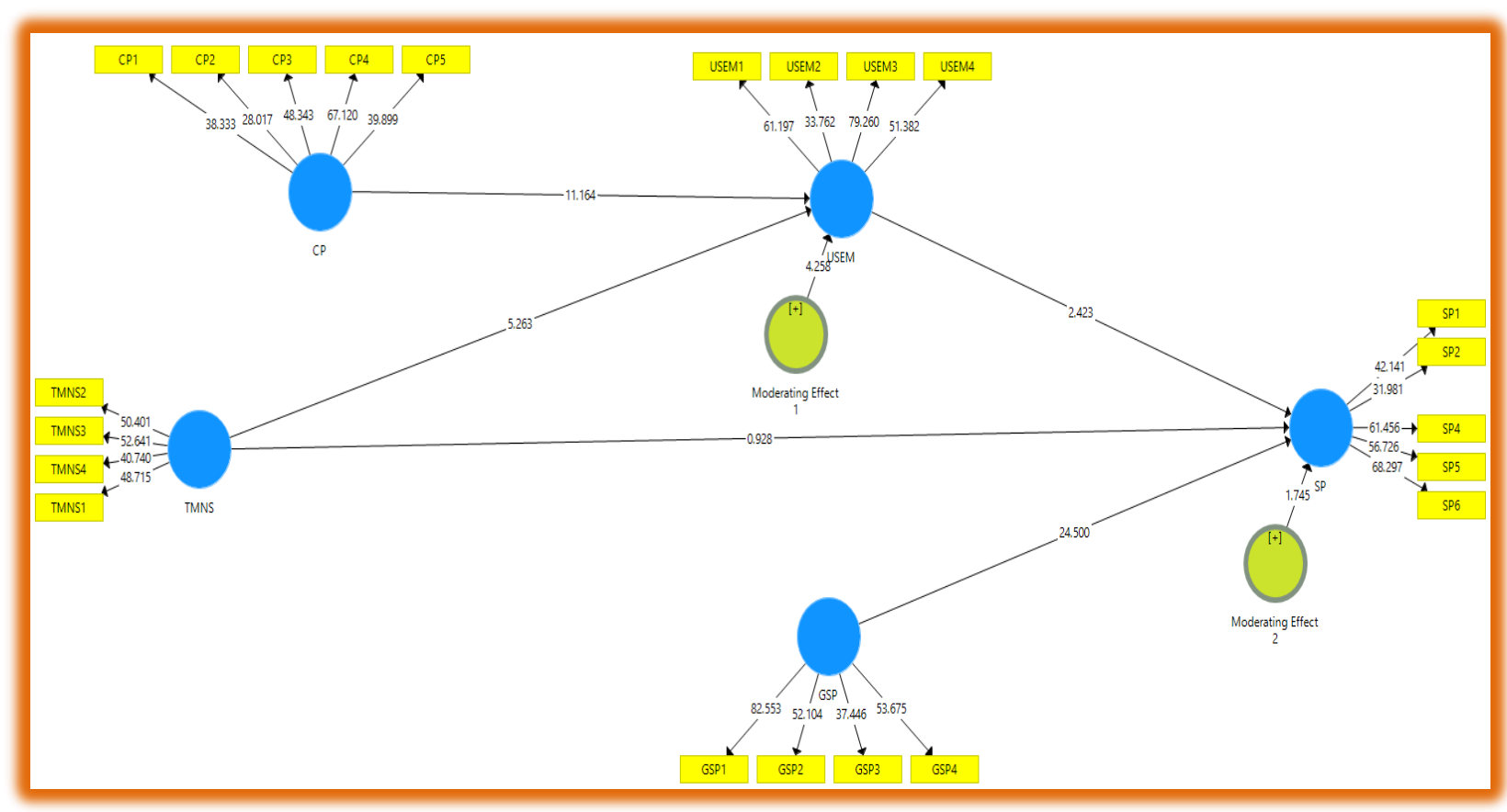

Figure 3. Structural Model.

Table 4. Direct and moderating results.

\begin{tabular}{|l|l|l|l|l|l|}
\hline & Beta & $\mathbf{M}$ & (STDEV) & $(\boldsymbol{| O} / \mathbf{S T D E V} \|)$ & P Values \\
\hline CP $>$ USEM & 0.666 & 0.668 & 0.060 & 11.164 & 0.000 \\
\hline GSP -> SP & 0.861 & 0.854 & 0.035 & 24.500 & 0.000 \\
\hline Moderating Effect 1 -> USEM & 0.068 & 0.068 & 0.016 & 4.258 & 0.000 \\
\hline Moderating Effect 2 -> SP & 0.029 & 0.030 & 0.017 & 1.745 & 0.041 \\
\hline TMNS -> SP & -0.073 & -0.070 & 0.079 & 0.928 & 0.177 \\
\hline TMNS -> USEM & 0.337 & 0.335 & 0.064 & 5.263 & 0.000 \\
\hline USEM -> SP & 0.193 & 0.198 & 0.080 & 2.423 & 0.008 \\
\hline
\end{tabular}

Table 5. Mediation

\begin{tabular}{|l|l|l|l|l|l|}
\hline & $\begin{array}{l}\text { Original } \\
\text { Sample (0) }\end{array}$ & $\begin{array}{l}\text { Sample Mean } \\
(\mathrm{M})\end{array}$ & $\begin{array}{l}\text { Standard Deviation } \\
\text { (STDEV) }\end{array}$ & $\begin{array}{l}\text { T Statistics } \\
(\text { OO/STDEV })\end{array}$ & $\begin{array}{l}\text { P } \\
\text { Values }\end{array}$ \\
\hline $\begin{array}{l}\text { TMNS -> USEM - } \\
>\text { SP }\end{array}$ & 0.065 & 0.066 & 0.028 & 2.296 & 0.011 \\
\hline
\end{tabular}


In this research, the $\mathrm{R} 2$ values of the criterion variable (work commitment) fulfil the criteria as presented in Table 6.

Table 6. R-square.

\begin{tabular}{|l|l|}
\hline & R Square \\
\hline SP & 0.864 \\
\hline USEM & 0.844 \\
\hline
\end{tabular}

Moreover, the predictive relevance of the model was also measured as suggested by (Hair et al,2014) to assess the model's quality. In Smart PLS software blindfolding is used for the estimation of predictive relevance. In blindfolding technique, few cases are omitted and manipulated as missing values for the estimation of parameters (Hair et al., 2014).

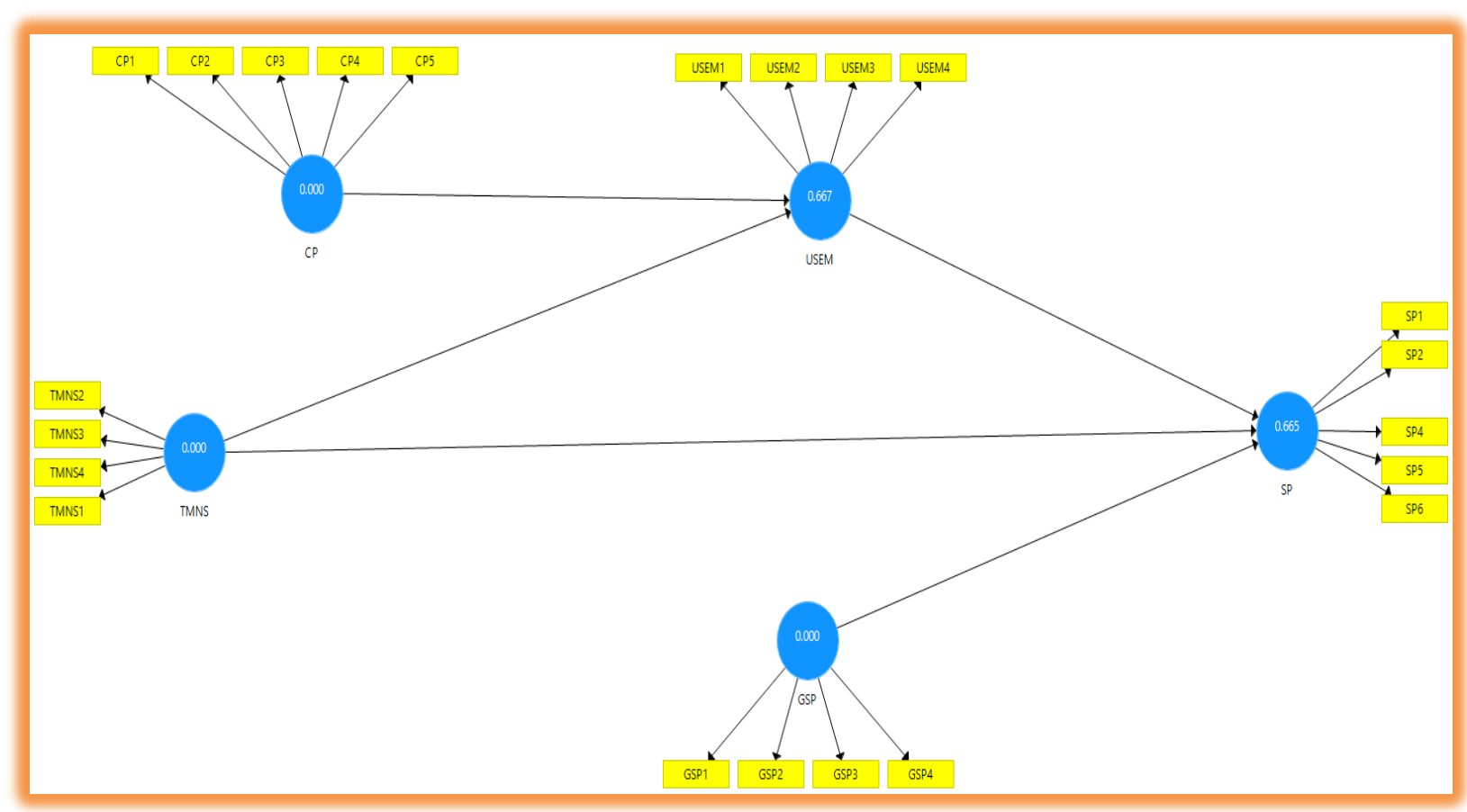

Figure 4. Q-square.

Table 6. $Q^{2}$

\begin{tabular}{|l|l|l|l|}
\hline & SSO & SSE & $\mathbf{Q}^{2}$ (=1-SSE/SSO) \\
\hline CP & $1,085.000$ & $1,085.000$ & \\
\hline GSP & 868.000 & 868.000 & \\
\hline SP & $1,085.000$ & 363.312 & 0.665 \\
\hline TMNS & 868.000 & 868.000 & \\
\hline USEM & 868.000 & 289.034 & 0.667 \\
\hline
\end{tabular}

Every business in the emerging country aims at achieving growth, which is sustainable in line with the practices of triple bottom line. In emerging countries, the businesses are making efforts to grow but less efficient in terms of e-marketing adoption and sustainability. The interactive role of CPs, GS, and CP between 
USEM, SFP, and TMNS has been analysed. The research has determined the role of USEM as a mediator between the relation of sustainable performance of business and TMNS. The theoretical framework has been laid down by this research through incorporating and linking DOI and RBV theory. In this way, this study has contributed to the current literature. It has been revealed by the findings that the CPs pressure act as a moderator between the relation of USEM and TMNS. Moreover, the relation between sustainable performance and USEM is moderated by CP. This study has developed some significant positive association between USEM, SFP, and TMNS as well as the relation between sustainable performance and TMNS is partially mediated by USEM. It reflects that the CP pressure is linked with the adoption of technology as it shows a crucial role in information sharing between the businesses through the support of top management in terms of technology (Chen, 2016). The pressure of CP has been highlighted in the research and it acts as a moderation in the relation of USEM and TMNS. The empirical relation between the CP pressure, technology, and TMNS is substantiated by the result. The previous research studies have shown the use of e marketing is influenced by CP in line with the outcomes of this research (Chen, 2016). The notion that competitive advantage and sustainable performance is achieved through making changes in the internal strategies and complying with the external environmental pressure is supported by this research. This is in line with the RBV.

\section{CONCLUSION}

This research has combined three crucial factors that enable the firm to achieve sustainable performance of business including customers, top management, and government. A complete plan of environment is established by the decision makers that needs the collaboration of suppliers and customers along with the adoption of environmental activities. Direct working relation should be built by the producers with the two partners for achieving the desired outcomes. This can improve the sustainable performance of business. The sports firms should comply with the policies of government, competitors' knowledge, and advanced technology along with adoption of e marketing. The overall goals of the firm towards sustainable performance can be affected by the failure to identify the value of external efforts in developing the economic, social, and environmental coloration within the partners of supply chain (Yawar \& Seuring, 2017). In Thailand, the sports firms have resulted in huge employment and ultimately the alleviation of poverty, economic growth. These are some of the issues related to triple bottom line. There is need for the policy makers and government to think about the decisions related to the sports sector, which can create a direct influence on the environmental and social activities. It is crucial to know about the actions of policy makers and government to enhance the sustainability and performance. However, the literature reveals that there is less use of e marketing activities in the sports sector of Thailand. Moreover, it can increase the market growth, customer relation, long-term sustainability, and development of new product, retention of customer, digital marketing, and communication at national and international level. From academic aspect, the study is unique as it is based on e marketing in general. It has analysed the influence of e marketing on the sustainable organizational performance. Empirical evidence has been provided by this study about the hypothesized relations in the research framework. The role of USEM as a mediator and CP and CPs as moderators has been signified in the relation of USEM and TMNS. Alternatively, the role of GS and TOP as a moderator has been analysed between the relation of SFP and USEM. The research implications are not limited to defining the RBV and DOI theory rather it aims at improving the firms' ability to implement the use of technology for higher sustainable business performance. The model can be extended by the future studies keeping the focus on the influence of USEM and TMNS on sustainable performance. The model can incorporate organizational, technological, and environmental framework in future studies along with their influence on USEM. Further, the mediators can be incorporated by future studies such as e business, innovation, or e commerce supported by the DOI an RBV theories. 


\section{REFERENCES}

Abu Bakar, A. R., \& Ahmed, Z. U. (2015). Technology motivation in e-marketing adoption among Malaysian manufacturers. Journal of Transnational Management, 20(2), 126-152. https://doi.org/10.1080/15475778.2015.1038949

Alsaad, A., Mohamad, R., \& Ismail, N. A. (2017). The moderating role of trust in business to business electronic commerce (B2B EC) adoption. Computers in Human Behavior, 68, 157-169. https://doi.org/10.1016/j.chb.2016.11.040

Ataullah, M., Sajid, A., \& Khan, M. (2014). Quality related issues and their effects on returns of Pakistan textile industry. Journal of Quality and Technology Managment, 10(I), 69-91.

Baumgartner, R. J., \& Rauter, R. (2017). Strategic perspectives of corporate sustainability management to develop a sustainable organization. Journal of Cleaner Production, 140, 81-92. https://doi.org/10.1016/j.jclepro.2016.04.146

Bi, R., Davison, R. M., \& Smyrnios, K. X. (2017). E-business and fast growth SMEs. Small Business Economics, 48(3), 559-576. https://doi.org/10.1007/s11187-016-9788-8

Cameron, E., \& Green, M. (2015). Making sense of change management: A complete guide to the models, tools and techniques of organizational change: Kogan Page Publishers.

Chen, Y. (2016). Industrial information integration-A literature review 2006-2015. Journal of Industrial Information Integration, 2, 30-64. https://doi.org/10.1016/j.jii.2016.04.004

Damanpour, F., Sanchez, F., \& Chiu, H. H. (2018). Internal and external sources and the adoption of innovations in organizations. British Journal of Management, 29(4), 712-730. https://doi.org/10.1111/1467-8551.12296

Davcik, N. S., \& Sharma, P. (2016). Marketing resources, performance, and competitive advantage: A review and future research directions. Journal of Business Research, 69(12), 5547-5552. https://doi.org/10.1016/i.jbusres.2016.04.169

Fitzgerald, B., \& Stol, K.-J. (2017). Continuous software engineering: A roadmap and agenda. Journal of Systems and Software, 123, 176-189. https://doi.org/10.1016/i.jss.2015.06.063

Georgios, T., \& Theoharis, D. (2017). Application of modern administration and marketing functions in the dominant Greek companies in food and drink branch. Paper presented at the 5 th International Conference on Contemporary Marketing Issues ICCMI June 21-23, 2017 Thessaloniki, Greece.

Hair, Hult, G. T. M., Ringle, C. M., \& Thiele, K. O. (2017). Mirror, mirror on the wall: a comparative evaluation of composite-based structural equation modeling methods. Journal of the Academy of Marketing Science, 45(5), 616-632. https://doi.org/10.1007/s11747-017-0517-x

Hair, Sarstedt, M., Hopkins, L., \& Kuppelwieser, V. (2014). Partial least squares structural equation modeling (PLS-SEM) An emerging tool in business research. European Business Review, 26(2), 106-121. https://doi.org/10.1108/ebr-10-2013-0128

Hair, J. F., Hult, G. T. M., Ringle, C., \& Sarstedt, M. (2016). A primer on partial least squares structural equation modeling (PLS-SEM): Sage publications. https://doi.org/10.3926/oss.37

Haseeb, M., Hussain, H., Slusarczyk, B., \& Jermsittiparsert, K. (2019). Industry 4.0: A Solution towards Technology Challenges of Sustainable Business Performance. Social Sciences, 8(5), 184. https://doi.org/10.3390/socsci8050154

Hawary, S., \& AIDafiri, M. (2017). Effect of the Components of Information Technology adoption on Employees Performance of Interior Ministry of Kuwait State. International Journal of Academic Mathematical, Engineering and Manage Sciences, 1(2), 77-88. https://doi.org/10.6007/ijarems/v6$\underline{\mathrm{i} 2 / 2811}$ 
Henseler, J., Ringle, C. M., \& Sarstedt, M. (2015). A new criterion for assessing discriminant validity in variance-based structural equation modeling. Journal of the Academy of Marketing Science, 43(1), 115-135. https://doi.org/10.1007/s11747-014-0403-8

Hyung, L., \& Dedahanov, A. (2014). Firm performance and entrepreneurial, market and technology orientations in korean technology intensive smes. Asian Social Science, 10(22), 37. https://doi.org/10.5539/ass.v10n22p37

Iddris, F., \& Ibrahim, M. (2015). Examining the relationships between e-Marketing adoption and Marketing Performance of Small and Medium Enterprises in Ghana. Journal of Marketing and Consumer Research, 10, 160-169.

Iqbal, M. S., Mahmood, B., \& Akhtar, M. N. (2017). Economic Impact of Energy Crisis on the Textile Sector: A Case Study of Pakistan. J. Appl. Environ. Biol. Sci., 7, 39-46.

Jameel, A., \& Ahmad, M. A.-A. (2018). Determine some factors that affect to adoption of e-commerce among small and medium enterprises in Erbil. Polytechnic Journal, 8(1). https://doi.org/10.25156/pti.2018.8.1.146

Jermsittiparsert, K. \& Srihirun, W. (2019). Role of Ethics in Supply Chain Management: Culture as Moderator. Humanities and Social Sciences Reviews, 7(3), 728-735. https://doi.org/10.18510/hssr.2019.73105

Jermsittiparsert, K., Sutduean, J., \& Sutduean, C. (2019). Sustainable Procurement \& Sustainable Distribution Influence the Organizational Performance (Economic, Social and Environmental): Moderating Role of Governance and Collaboration at Thai Food Industry. International Journal of Supply Chain Management, 8(3), 83-94.

Kamali, M., \& Hewage, K. (2017). Development of performance criteria for sustainability evaluation of modular versus conventional construction methods. Journal of Cleaner Production, 142, 3592-3606. https://doi.org/10.1016/j.jclepro.2016.10.108

Kowo, S. A.; Adenuga, O. A. O.; Sabitu, O.O. 2019. The role of SMEs development on poverty alleviation in Nigeria, Insights into Regional Development 1(3): 214-226. https://doi.org/10.9770/ird.2019.1.3(3)

Lowry, P. B., \& Wilson, D. (2016). Creating agile organizations through IT: The influence of internal IT service perceptions on IT service quality and IT agility. The Journal of Strategic Information Systems, 25(3), 211-226. https://doi.org/10.1016/i.jsis.2016.05.002

Najam, U., Awan, H., \& Abbas, M. (2018). The interactive role of temporal team leadership in the telecom sector of Pakistan: Utilizing temporal diversity for sustainable knowledge sharing. Sustainability, 10(5), 1309. https://doi.org/10.3390/su10051309

Pappu, R., \& Quester, P. G. (2016). How does brand innovativeness affect brand loyalty? European Journal of Marketing, 50(1/2), 2-28. https://doi.org/10.1108/ejm-01-2014-0020

Pinho, S. R. (2015). Reaching customers for online services.

Rahayu, R., \& Day, J. (2015). Determinant factors of e-commerce adoption by SMEs in developing country: evidence from Indonesia. Procedia-Social and Behavioral Sciences, 195, 142-150. https://doi.org/10.1016/j.sbspro.2015.06.423

Sadeghi, M. T., Sobhani, F. M., \& Ghatari, A. R. (2017). Representing a Model to Measure Absorbency of Information Technology in Small and Medium Sized Enterprises. Information Systems \& Telecommunication, 242.

Sadeh, F., \& Kacker, M. (2018). Quality signaling through ex-ante voluntary information disclosure in entrepreneurial networks: Evidence from franchising. Small Business Economics, 50(4), 729-748. https://doi.org/10.1007/s11187-017-9892-4

Sheikh, A. A., Shahzad, A., \& Ishak, A. B. K. (2016). The mediating impact of e-marketing adoption on export performance of firms: A conceptual study. Journal of Technology and Operations Management, 11(1), 48-58. 
Sheikh, A. A., Shahzad, A., \& Ishaq, A. K. (2017). The growth of e-marketing in business-to-business industry and its effect on the performance of businesses in Pakistan: Marketing success. International and Multidisciplinary Journal of Social Sciences, 6(2), 178-214. https://doi.org/10.17583/rimcis.2017.2704

Sheikh, A. A., Shahzad, A., \& ku Ishak, A. B. (2017). The role of e-marketing uses among TOE factors and textile sector performance in Pakistan: An empirical study. NUML International Journal of Business \& Management, 12(2), 117-135.

Śmigielska, G. (2018). A business case for sustainable development. CES Working Papers, 10(1), 4966.

Snyder, K., \& Hilal, P. (2015). The changing face of B2B marketing. Think with Google. Think with Google. Spreer, P., \& Rauschnabel, P. A. (2016). Selling with technology: understanding the resistance to mobile sales assistant use in retailing. Journal of Personal Selling \& Sales Management, 36(3), 240-263. https://doi.org/10.1080/08853134.2016.1208100

Sutduean, J., Joemsittiprasert, W., \& Jermsittiparsert, K. (2019). Exploring the Nexus between Information Technology, Supply Chain and Organizational Performance: A Supply Chain Integration Approach. International Journal of Innovation, Creativity and Change, 5(2), 249-265. https://doi.org/10.18510/hssr.2019.73102

Tiago, M. T. P. M. B., \& Veríssimo, J. M. C. (2014). Digital marketing and social media: Why bother? Business horizons, 57(6), 703-708. https://doi.org/10.1016/j.bushor.2014.07.002

Ueasangkomsate, P. (2015). Adoption e-commerce for export market of small and medium enterprises in Thailand. Procedia-Social and Behavioral Sciences, 207, 111-120. https://doi.org/10.1016/j.sbspro.2015.10.158

Vafaei, S. A., Azmoon, I., \& Fekete-Farkas, M. (2019). The impact of perceived sustainable marketing policies on green customer satisfaction. Polish Journal of Management Studies, 19. https://doi.org/10.17512/pims.2019.19.1.36

Wagdi, O., Hasaneen, A. 2019. Obstacles and success factors for entrepreneurship: a comparative analysis between Egypt and Nigeria. Entrepreneurship and Sustainability Issues, 7(2), 962-976. http://doi.org/10.9770/jesi.2019.7.2(12)

Wong, J. K. W., \& Zhou, J. (2015). Enhancing environmental sustainability over building life cycles through green BIM: A review. Automation in Construction, 57, 156-165. https://doi.org/10.1016/i.autcon.2015.06.003

Yawar, S. A., \& Seuring, S. (2017). Management of social issues in supply chains: a literature review exploring social issues, actions and performance outcomes. Journal of Business Ethics, 141(3), 621643. https://doi.org/10.1007/s10551-015-2719-9

Yigitcanlar, T., \& Teriman, S. (2015). Rethinking sustainable urban development: towards an integrated planning and development process. International Journal of Environmental Science and Technology, 12(1), 341-352. https://doi.org/10.1007/s13762-013-0491-x 